\title{
Real-Time Forecasting of EV Charging Station Scheduling for Smart Energy Systems
}

\author{
Bharatiraja Chokkalingam ${ }^{1}$, Sanjeevikumar Padmanaban ${ }^{2, *}$, Pierluigi Siano ${ }^{3, *}$, \\ Ramesh Krishnamoorthy ${ }^{4}$ and Raghu Selvaraj ${ }^{5}$ \\ 1 Department of Electrical and Electronics Engineering, SRM University, Chennai 603 203, India; \\ bharatiraja@gmail.com \\ 2 Department of Electrical and Electronics Engineering, University of Johannesburg, Auckland Park, \\ Johannesburg 2006, South Africa \\ 3 Department of Industrial Engineering, University of Salerno, Salerno 84084, Italy \\ 4 Department of Electronics and Communication Engineering, SRM University, Chennai 603 203, India; \\ rameshk.tn@gmail.com \\ 5 Department of Water Resource Development and Management, Indian Institute of Technology, \\ Roorkee 247 667, India; raghu.selvaraj89@gmail.com \\ * $\quad$ Correspondences: sanjeevikumarp@uj.ac.za (S.P.); psiano@unisa.it (P.S.); Tel.: +27-79-219-9845 (S.P.)
}

Academic Editor: Chunhua Liu

Received: 7 November 2016; Accepted: 13 March 2017; Published: 16 March 2017

\begin{abstract}
The enormous growth in the penetration of electric vehicles (EVs), has laid the path to advancements in the charging infrastructure. Connectivity between charging stations is an essential prerequisite for future EV adoption to alleviate user's "range anxiety". The existing charging stations fail to adopt power provision, allocation and scheduling management. To improve the existing charging infrastructure, data based on real-time information and availability of reserves at charging stations could be uploaded to the users to help them locate the nearest charging station for an EV. This research article focuses on an a interactive user application developed through SQL and PHP platform to allocate the charging slots based on estimated battery parameters, which uses data communication with charging stations to receive the slot availability information. The proposed server-based real-time forecast charging infrastructure avoids waiting times and its scheduling management efficiently prevents the EV from halting on the road due to battery drain out. The proposed model is implemented using a low-cost microcontroller and the system etiquette tested.
\end{abstract}

Keywords: electric vehicle (EV); charging station (CS); state of charge (SOC); structured query language (SQL); personal home page (PHP)

\section{Introduction}

There is currently a focus on electric vehicles due to their eco-friendly benefits such as low $\mathrm{CO}_{2}$ emissions and decreased demand for fossil fuels and gases. It emerges that for the transportation system to concentrate on EVs attention must be paid to the power network to utilize economies of scale in their energy consumption. Unlike traditional vehicles, EVs don't require such high maintenance costs $[1,2]$ and moreover, they have great potential advantages such as cost, convenience, travel range and charging infrastructure. A compact, mid-family size car battery-based $22-32 \mathrm{kWh}$ package runs the EV for about 40-100 miles. The Toyota RAV4 electric cars with a rated battery size of $41.8 \mathrm{kWh}$ provides a driving range of 113 miles with a full energy charge. Hybrid electric vehicles utilize the combination of an internal combustion engine (ICE) and an electrical propulsion system to achieve a speed range of 29.93 kilometers per hour. The Chevrolet Volt officially unveiled an $18.4 \mathrm{kWh}$ battery with fuel cell usage, to improve the driving range from 38 to 53 miles/charge. A $120 \mathrm{~V}$ single phase system charging 
outlet with on board charging technology requires $11-36 \mathrm{~h}$ to charge a 16-50 $\mathrm{kWh}$ battery system for a driving range of 40 miles. Commercial public or private charging systems use 208-600 V systems to charge a $20-50 \mathrm{kWh}$ battery in $0.2-0.5 \mathrm{~h}$ [1]. The global EV manufacturers have concentrated on developing the zero carbon emission vehicles with improved performance characteristics, driving the demand for EVs with compact energy efficient and low cost cut off [2].

The compactness of the current EV power train only provides the capability for a short driving range. The researchers concentrating on the enhancement of the power train capability are focused on increasing the driving range to $500 \mathrm{~km}$ with a rated battery capacity of $75 \mathrm{kWh}$. The enhancement makes the system exceedingly complex with an added increase in the cost. Figure 1 gives an idea about the relation between the propulsion system and battery packages.

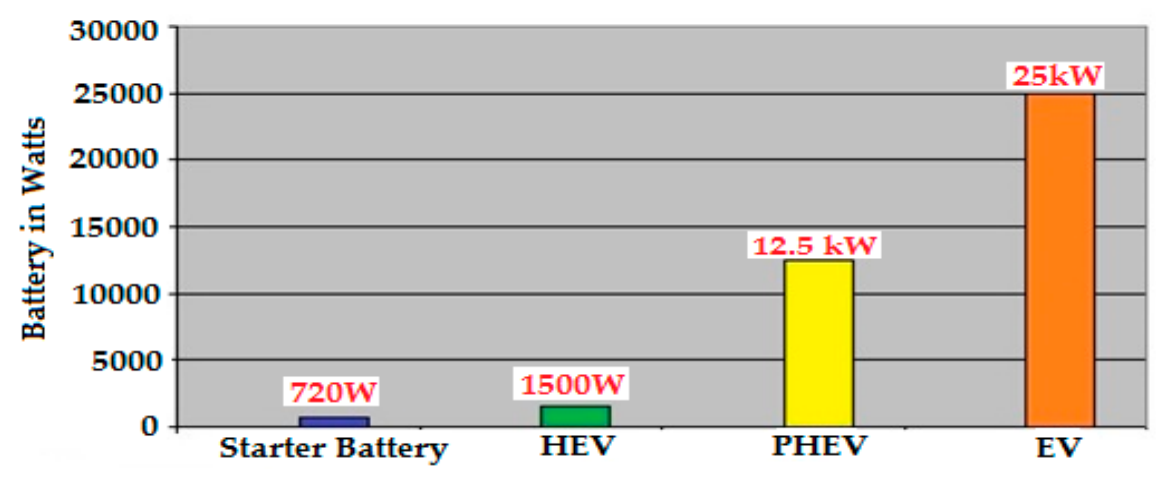

Figure 1. Electric propulsions versus energy consumption.

The various EV propulsion trends can be summarized as $720 \mathrm{~W}$ starter battery, $1500 \mathrm{~W}$ hybrid electric vehicles (HEV), PHEV with $12.5 \mathrm{~kW}$ and an EV with $25 \mathrm{~kW}$ [3]. Cousland et al. planned the monitoring and control of lithium-ion cells [4]. Haghbin et al. surveyed the literature on various compact battery chargers for EV applications [5]. In level-1 charging infrastructures, the users predominately use the night time to power up the $\mathrm{EV}$ with their portable single phase outlets. Semi-fast charging EVs can be plugged in $240 \mathrm{~V}$ single or three phase public or private outlets and take 2 to $6 \mathrm{~h}$ to charge to a full usable capacity. A pictorial view of several EV charging levels is shown in Figure 2.

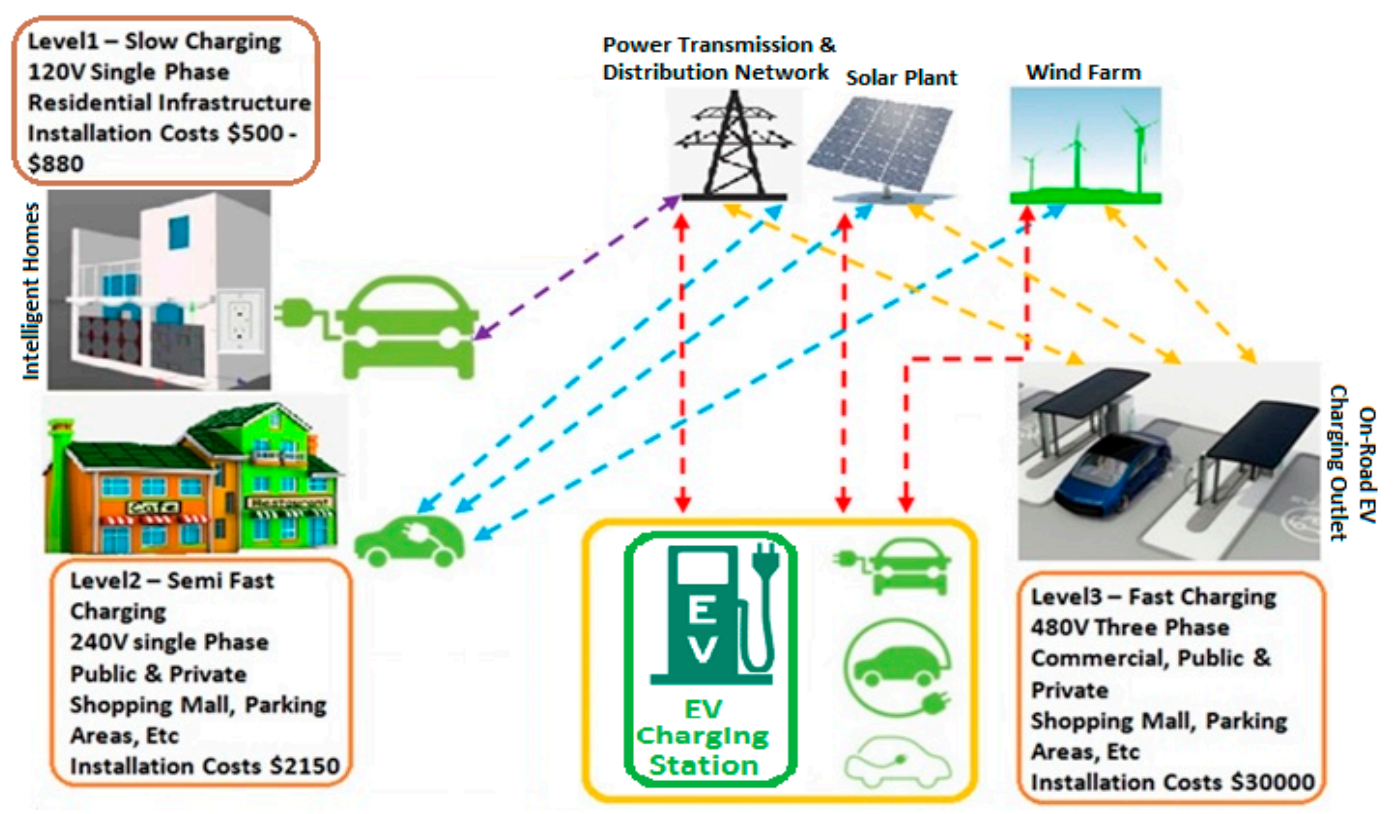

Figure 2. Levels of charging requirements. 
From the commercial view points, EVs must indeed charge fast within a short span of time. The various charging systems receive power from the grid or from high penetration renewable energy sources integrated with the charging system to maintain the grid flexibility [6]. Verzijlbergh et al. have identified the optimized strategy for EV charging and discharging based on the peak power demand for flexible operation of the power grid [7]. The EV battery performance is estimated and communicated to the user regularly to avoid battery drain out. The battery performance is analysed through the SOC technology. Chang et al. reviewed various battery SOC estimation methods and concluded that the Coulomb counting method is efficient for storage systems [8]. Future transportation systems will focus strongly on vehicle to vehicle (V2V), vehicle to infrastructure (V2I), a vehicle to grid (V2G) communication and vice versa [9]. The data communication deliberately uses the two-way communication between user and charging station for scheduled power management. The SOC of the EV is estimated using the user interface which is communicated to the next-door charging station to allocate a power provision slot based on distributed system power demand [10,11]. Research has been conducted to forecast $\mathrm{EV}$ vehicle battery power management to best utilize the advantages of the charging process $[12,13]$. However, these concepts are not included in the dynamic charge scheduling management facilities based on the vehicle location and SOC [14-16]. In order to achieve this, the vehicle and charging station communicate with each other for the reservation of slots according to the availability and the cost functions [17]. The progress in EVs in the near future is expected to be high and must be supported with the help of available and future communication systems [18-20]. The proposed real-time EV charge scheduling depends upon the battery dynamics and availability of charging slots. Based on the scheduling management facility, the system will deliver the information to the user regarding the nearest charging station, best cost function and booking slots with respect to estimated vehicle battery SOC. The information sharing through webpages allows the energy management system to respond based on the vehicle peak demand and the vendor perspective $[20,21]$. The webpage is developed based on PHP scripting, which helps the user view the aforementioned information. With this, the vendors can even sell their services by means of bidding processes which can be done by adding the charging station through an online GPRS map. Therefore the viewer can choose the nearest charging station and available slots based on cost per unit. Here the coulomb counting method is used to estimate the SOC and the database is created in the SQL form with the purpose of storing information like SOC, the cost of charge, cost per $\mathrm{kWh}$ for the prevailing average rate, etc. The database is linked to a webpage which keeps track of information and transfers to the user by means of 3G/4G networks, or Wi-Fi protocols. Our analysis begins with a discussion of load forecasting in Section 2. This is followed by the SOC measurement in Section 3 and communication network architecture in Section 4. Section 5 deals with system topology, which is followed by computational algorithm development for server interfacing.

\section{Load Forecasting}

A load consumption graph can be used to improve the energy management system and also strengthen the resourcefulness of the proposed approach. This will help to overcome energy supply shortages on the vendor side and avoid inconveniences for the user as well. The following are arbitrary samples of load forecasting at charging stations in different regions directed to the user [10]. These samples will help to predict the peak hour demand, the number of customers expected during the precise time of the day. Figure 3 a shows that the increase in charging rates will change according to the peak demands. The particular station will have high demand during a specific time interval where other stations will not, as shown in Figure 3b.

The unit cost variations in those stations vary accordingly as shown in Figure 3c. To reduce these variations the proposed communication network setup will work in such way that it will inform the user about the availability of charging slots and charging stations with the purpose of helping the user save time for selecting a preferred station where there is availability (see Figure $3 \mathrm{~d}$ ). 


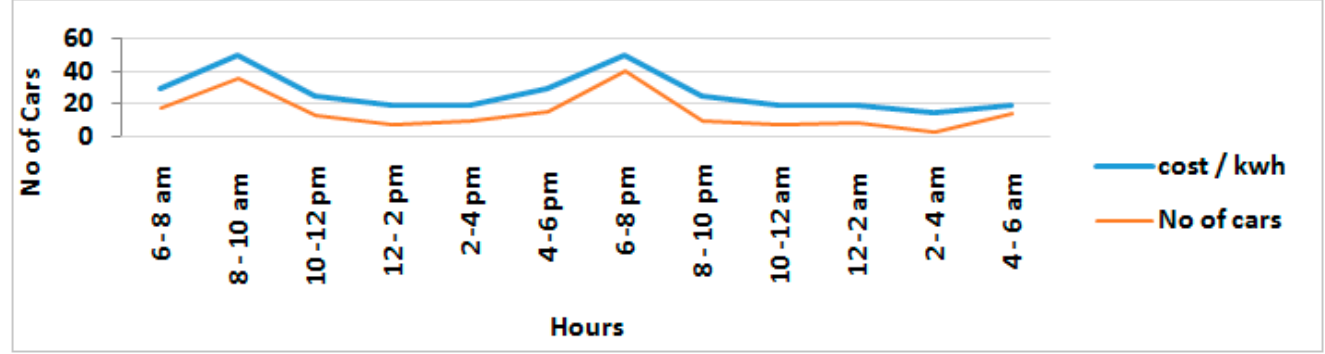

(a)

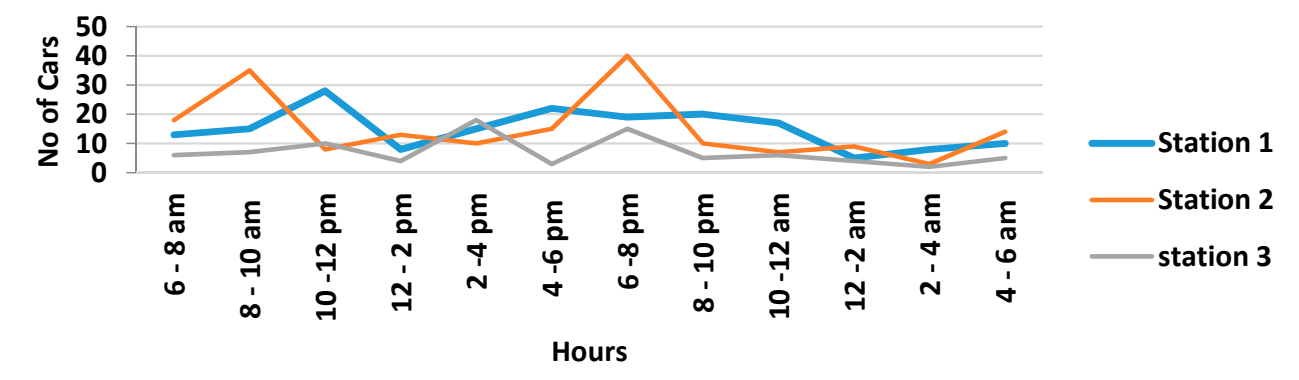

(b)

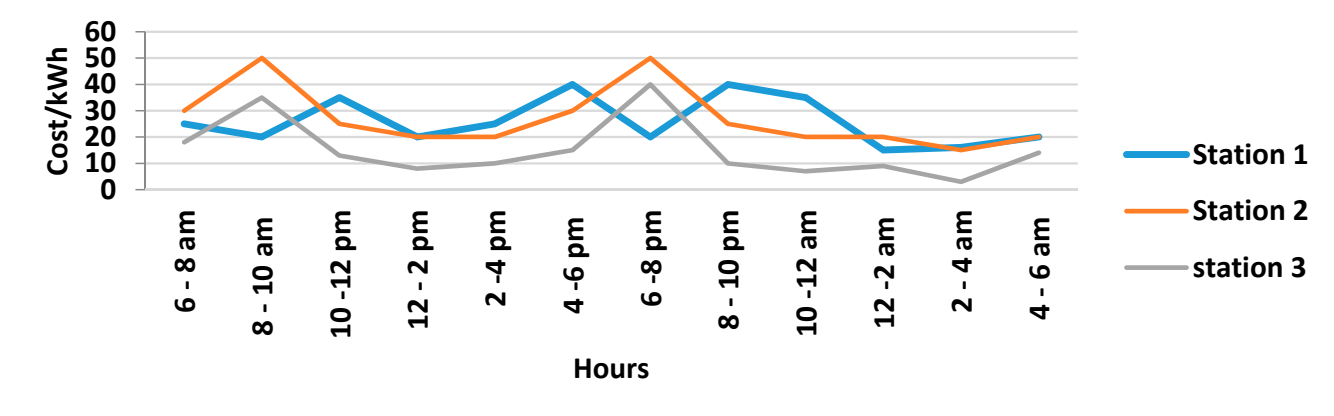

(c)

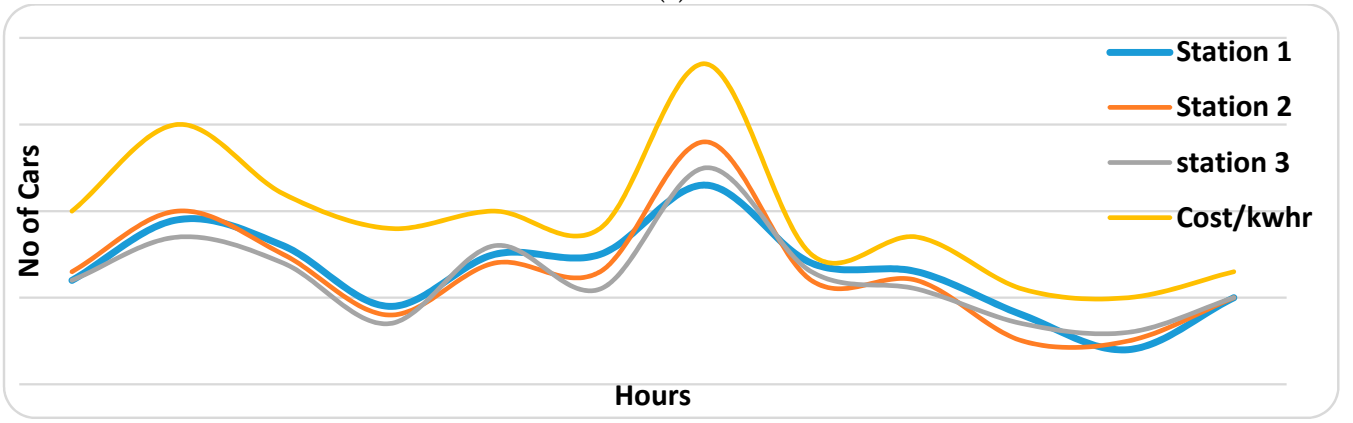

(d)

Figure 3. (a) The increase in cost/kWh as the number of vehicles increases; (b) Peak demands at three different stations; (c) Cost per kWh of charging in three different stations; (d) Stabilized peak demand and cost per $\mathrm{kWh}$ in all three stations.

Implementing this model would improve the energy management system of the grid, as the peak demands at each station are equally distributed, while the cost per kWh will not vary to a large extent. The charging stations form an essential part of the EV reliability scenario in addition to energy utilization. With respect to the present EV market, the major shortcoming is that there are not sufficient charging stations to cater to the need $[17,22]$. This is further aggravated by the fact that the locations of these charging stations are not uniform. Thus EV usage is currently limited to particular countries or states. When users drive out of state, they may not find abundant charging stations at regular intervals. 
Apart from these issues, there are other problems related to the power distribution to several customers during peak hours. Since EVs take several hours to charge their battery, the user has to occupy a charging slot in a station for a considerable amount of time, yet when the vendor employs a method to forecast load at peak hours, there may not be sufficient charging slots to hold many customers simultaneously. Thereby, knowing the availability of charging slots during a particular time will avoid traffic at charging stations during peak hours. As a result of the insufficiency of charging stations, energy distribution and peak hour load forecasting will pose an inconvenience for EV users.

\section{State of Charge Measurement}

Users expect that the vehicles will measure the present SOC of the battery and communicate it at any time. There are several methods to evaluate the SOC of a battery [8]. The method proposed is straightforward and convenient as it uses Arduino codes where the outputs are obtained in digital format. Unlike the lithium-ion batteries used in laptops and smartphones, which uses smart chips inserted within them to measure SOC, the lead acid batteries used in EVs cannot do the same. Their SOC can only be measured externally (using the terminal voltage), so the Arduino is programmed to continuously measure the SOC and is looped within time delays to keep running the program. This updated SOC data should be communicated to the user, which involves transmitting the data from the Arduino to a smartphone. This data becomes essential as it determines the remaining capacity of the battery, the maximum possible distance the vehicle can traverse with the current SOC of battery, also the speed at which the EV can be operated to derive maximum desired output-either in terms of speed or distance. SOC refers to indicating whether the battery is fully or partially charged. The remaining SOC percentage will be displayed after computation using some appropriate method. It is necessary to estimate this so consequently the user can plan for travel based on the available SOC, otherwise the user should wait and charge the vehicle. There are lots of ways to measure the SOC of the battery; the preferred ones are Amp-Hour or Watt-Hour or the Coulomb Counting method.

\section{Coulomb Counting Method}

The battery charge is measured before and after discharging and integrated over time using Ampere-hours (Ah). SOC can be calculated by measuring the current in and out of the battery during charging/discharging with respect to the time of current flow [8,22]:

$$
\mathrm{SOC}=\frac{\text { Remaining Capacity }}{\text { Rated Capacity }}
$$

If the Ah capacity is used, the change of SOC can be expressed as:

$$
\mathrm{SOC}=\operatorname{SOC}(\mathrm{t})-\operatorname{SOC}\left(\mathrm{t}_{0}\right)=\frac{1}{\text { Ah Capacity }} \int_{\mathrm{t} 0}^{\mathrm{t}} \mathrm{i}(\mathrm{t}) \mathrm{dt}
$$

SOC is a critical condition parameter for battery management. Accurate gauging of SOC is very challenging, but key to the healthy and safe operation of batteries [23]. Figure 4 shows an EV Battery SOC profile. Here the voltage limitation is essential to avoid the generalized problems outlined in literatures are taken into consideration for the operating range of the SOC. Less than $20 \%$ and more than $90 \%$ of SOC limits are harmful to the battery lifetime [24].

Here the method (Coulomb Counting) used to be more accurate with lithium ion batteries is by using constant current charging method for ensuring the SOC in within the recommend range of values. The estimation of battery SOC is defined as:

$$
\mathrm{SOC}=\frac{\mathrm{Q}_{\mathrm{T}}-\mathrm{Q}_{\mathrm{D}}}{\mathrm{Q}_{\mathrm{T}}} \times 100 \%
$$


where $Q_{T}$ is the charge available before discharging of the battery, $Q_{D}$ is the existing charge during discharging of the battery. The measurement of the current entering and leaving the battery during charge and discharge of the battery is called the Coulomb method because 1 Amp of current flowing for $1 \mathrm{~h}$ is equal to 3600 coulomb. $1 \mathrm{Ah}=3600 \mathrm{C}$, as a Coulomb is defined as the one Ampere of current following in one second. Watt-hour is the battery voltage multiplied by the Ampere-hour value. This is used to calculate the rate for charging the battery.

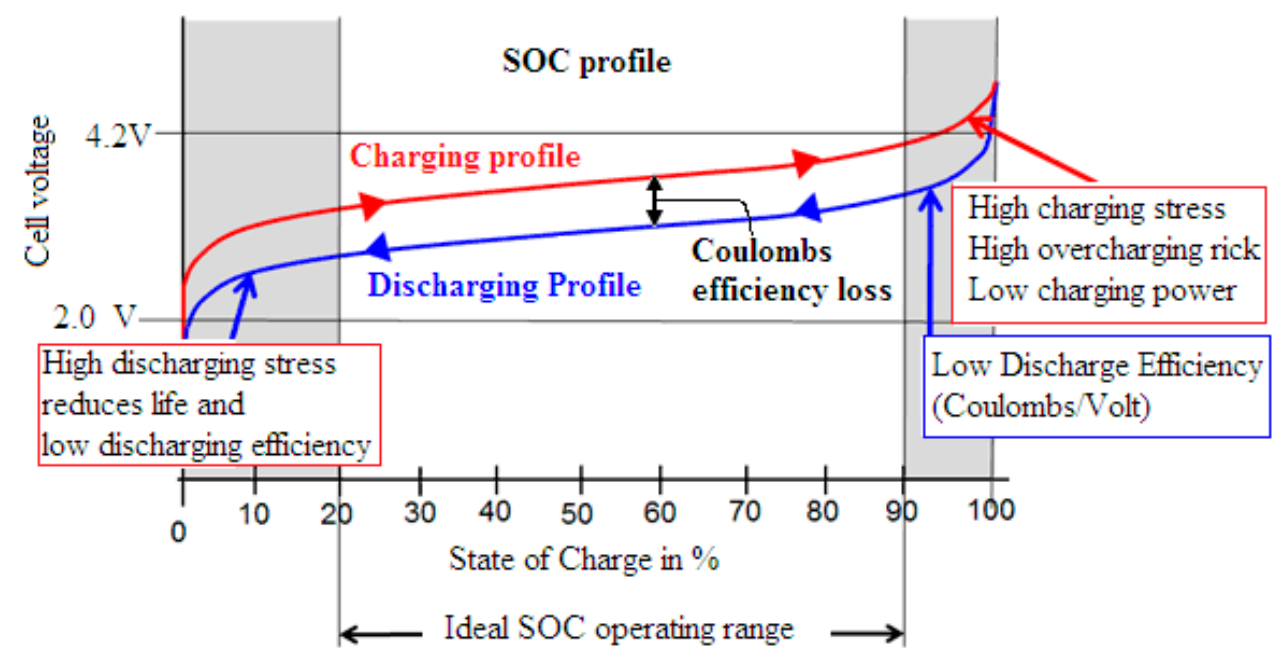

Figure 4. EV Battery SOC profile.

\section{Communication Network Architecture}

The transfer of information between two devices is carried out through wired or wireless means. The information is first stored for future consideration in a storage device (server), which is connected to another device (client). In wired communication there is a physical connection between the two devices, whereas the wireless communication will not have any physical connection in between the devices. In this system, communication takes place between the server or cloud and the user's mobile devices through Wi-Fi/ZigBee/GSM networks. To enjoy all the benefits of smart EV charge scheduling, decisions must be taken at the right time in order to optimize the overall system. The EV charging control system consists of several network devices that work mutually to ensure optimal charging of EVs and grid robustness [1].

Figure 5 shows the communication network architecture, where the electric power from the grid is controlled from the power station and fed into the user end, and through the gateway, the power is transferred to the Electric Vehicle Supply Equipment (EVSE), and other applicable entities. The EV charging station systems operate through the cloud, or with efficient Internet access. EVs will communicate with the EVSE through wireless interfaces like ZigBee or wired interfaces like RS232, ethernet, etc. The EV charging points will be able to interact themselves through the ZigBee protocol. Whenever an EV reaches the charging station, SOC is initially communicated with the EVSE to make a decision in assigning the slot to that particular EV. The SAE J1772 Electric Vehicle Connector communicates with the vehicle by means of the charging cable. The unique user and vehicle information are communicated using a smartphone with Internet availability. The SAE J1772 standard is used for connecting EVs with EVSEs and ensures system safety requirements and network interfaces through cables. The data sharing between the EV and EVSE is carried out through the J1772 connector using a wired interface. Table 1 lists the SAE standard codes and norms for EV batteries and interfaces. 


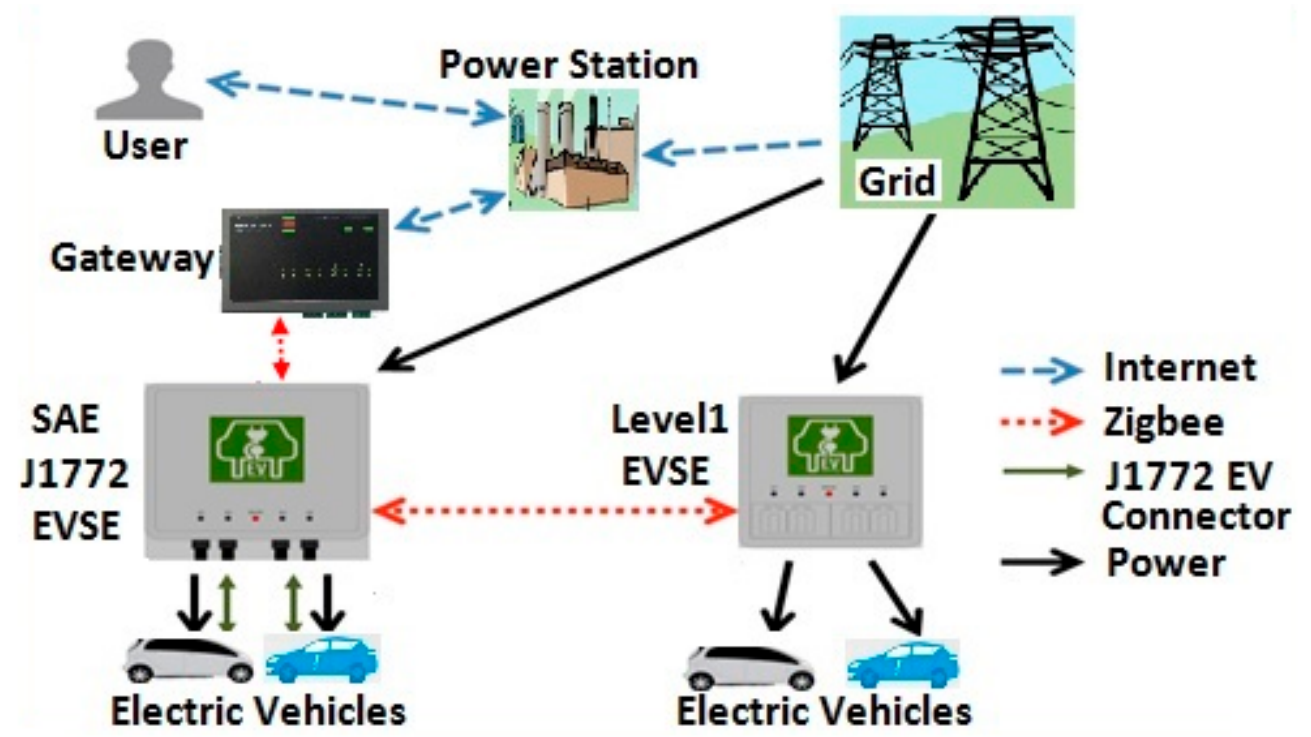

Figure 5. Communication Network Architecture.

Table 1. Communication Network: SAE standard codes for EV batteries and interfaces.

\begin{tabular}{|c|c|}
\hline SAE J-1766 & $\begin{array}{l}\text { Recommended Practice for Electric and Hybrid Electric Vehicle Battery Systems } \\
\text { Crash Integrity Testing }\end{array}$ \\
\hline SAE J-1797 & Recommended Practice for Packaging of Electric Vehicle Battery Modules \\
\hline SAE J-1798 & $\begin{array}{l}\text { Recommended Practice for Performance Rating of Electric Vehicle Battery } \\
\text { Modules }\end{array}$ \\
\hline SAE J-2288 & Life Cycle Testing of Electric Vehicle Battery Modules \\
\hline SAE J-2289 & Electric Vehicle Battery Pack System: Functional Guidelines \\
\hline SAE J-2380 & Vibration Testing of Electric Vehicle Batteries \\
\hline ISO/CD 12405-1 & $\begin{array}{l}\text { Electrically propelled road vehicles-Test specification for lithium-ion traction } \\
\text { battery packs and systems-Part1 High power applications }\end{array}$ \\
\hline SAE J-1772 & SAE Electric Vehicle Conductive Charge Coupler \\
\hline SAE J-1773 & SAE Electric Vehicle Inductive Coupled Charging \\
\hline SAE J-1850 & Class B Data Communications Network Interface \\
\hline SAE J-2293 Part 2 & $\begin{array}{l}\text { Energy Transfer System for EV Part2: Communication Requirements and } \\
\text { Network Architecture }\end{array}$ \\
\hline SAE J-2836 Part 1 & Use Cases for Communications between Plug-In Vehicles and Utility Grid \\
\hline SAE J-2836 Part 2 & $\begin{array}{l}\text { Use Cases for Communications between Plug-In Vehicles and the Supply } \\
\text { Equipment (EVSE) }\end{array}$ \\
\hline SAE J-2836 Part 3 & $\begin{array}{l}\text { Use Cases for Communications between Plug-In Vehicles and the Utility Grid for } \\
\text { Reverse Flow }\end{array}$ \\
\hline SAE J-2847 Part 1 & Communications between Plug-In Vehicles and Utility Grid \\
\hline SAE J-2847 Part 2 & Communications between Plug-In Vehicles and the Supply Equipment (EVSE) \\
\hline SAE J-2847 Part 3 & Communications between Plug-In Vehicles and the Utility Grid for Reverse Flow \\
\hline
\end{tabular}

The proposed system as shown in Figure 6 consists of an Arduino Microcontroller (MC) with the aim of determining SOC, charging cost and unit cost and avoiding unexpected exceptions and protecting batteries from excess charging and discharging so as to increase the battery lifetime. 


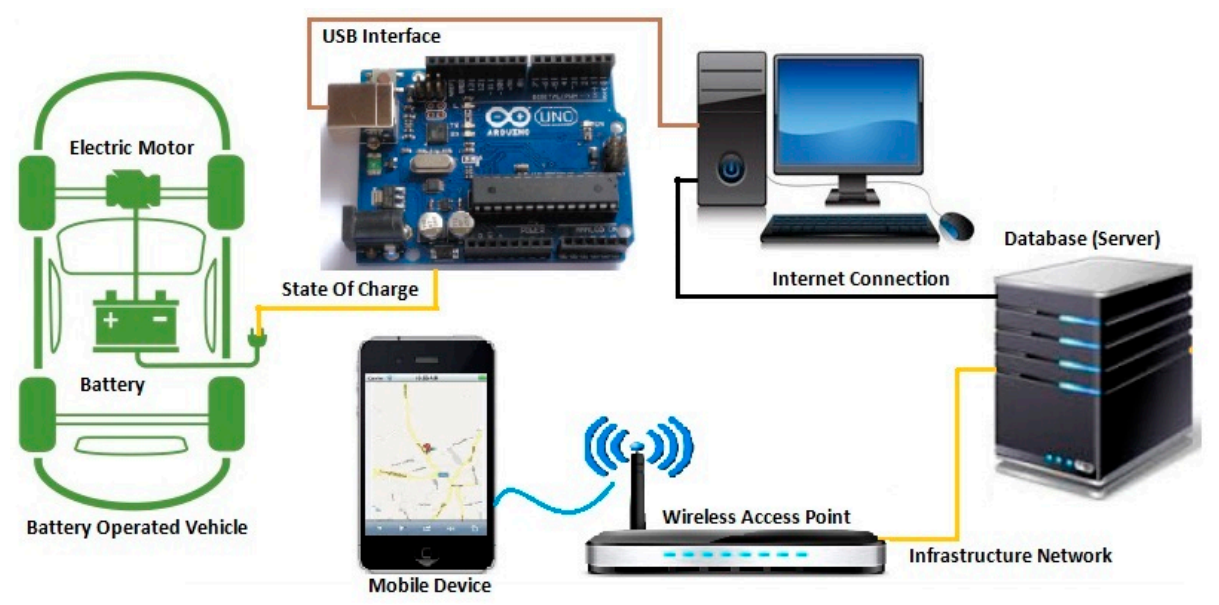

Figure 6. Schematic of the system.

As explained in Section 3 the Coulomb counting method is used to estimate the value of SOC. From the Arduino-MC the SOC is transferred to a personal computer/laptop USB port in order to monitor the status of the battery. The PC in the charging position is connected with a WiFi-enabled Internet connection. Thus the SOC transferred by the Arduino is read by the PC and stored in the database server and the same will be received by the mobile device of the particular EV user. The database is in the configuration of a SQL server, which will store SOC, the cost of charge, and cost per $\mathrm{kWh}$ for customary average rates and routes of travel. There is another database which will keep track of the charging stations and present the travel route plan. These databases are concurrent with the created webpage and display it through a WiFi-enabled Internet connection of 3G/4G/WiFi/ZigBee, etc. This webpage can show the map (place) at which the charging station is located and connects to the Googlemaps based on the user request. The Arduino board is interfaced to the PC through the USB cable. The entire system code is written by means of Embedded $C$ language. The database is linked with a user-friendly webpage. The system operates with a baud rate (number of bits transferred per second) of 9600 BPS, to connect the Arduino with the PC. Then the measured SOC from the Arduino is transferred without any issues. After initializing the baud rate, measured values of all the functions is initialized to zero to have a preventative measure to protect saved data. The battery input is applied to the analog input pins of the Arduino (voltage input of either $5 \mathrm{~V}$ or $3.3 \mathrm{~V}$ ) through the voltage divider circuit.

The Amp-hour of the battery is $400 \mathrm{mAh}$. This means that the battery will deliver $400 \mathrm{~mA}$ for one hour; this is said to be the initial charge or initial Ah of the battery. For the experimental setup a $9 \mathrm{~V}$, $68 \mathrm{~mA}$ DC motor is used as the load, therefore the motor can run for $5 \mathrm{~h}$ at the rate of $68 \mathrm{~mA}$, or run for an even longer time depending upon the usage. The battery should be recharged after $30 \%$ usage and maintain the load below $25 \%$ of the rated current inorder to have an extended life of usage of the battery, so the $\mathrm{C}$ rate (determined rate at which a battery is released relative to its utmost capacity) of this battery is $5 \mathrm{C}$. The amp hour is obtained by the Arduino by calculating the current flow and time of flow and multiplying it. Then the remaining amp-hour is obtained by the difference between initial and final amp hours:

$$
\text { Remaining Amphours }=(\text { Initial }- \text { Final }) \text { Amp Hour }
$$

Then SOC is calculated by the ratio between the remaining value and the initial value of Amp-hours of the battery:

$$
\text { SOC }=\frac{\text { Remaining Amp }- \text { hour }}{\text { Initial Amp }- \text { hour }} \times 100 \%
$$




$$
\text { Kilo watt hour }=\text { Battery voltage } \times \text { Amp Hour }
$$

$$
\text { Cost of charging the battery }=\mathrm{kWh} \times \text { Cost per } \mathrm{kWh}
$$

These parameters are processed and then imported to the database and then sent to the webpage. The information concerning the charging stations is created in the database separately by gathering tariff data from the charging stations and updating it into the database and presenting it to the users.

For estimation, a $9 \mathrm{~V}$ battery is used, the initial Ampere hours of the battery is $400 \mathrm{mAh}$. Table 2 illustrates that if the motor is driven for an hour, it utilize $68 \mathrm{mAh}$. Hence the observed value of battery SOC is $99.83 \%$. i.e., $0.17 \%$ has been used and hence the observed $\mathrm{kWh}$ is $0.612 \mathrm{kWh}$.

Table 2. Observed Values.

\begin{tabular}{cc}
\hline Ampere Hour & $68 \times 1=68 \mathrm{mAh}$ \\
SOC & $(68 / 400) \times 100=99.83 \%$ \\
kWh & $68 \times 9=0.612$ \\
\hline
\end{tabular}

\section{Algorithm for SOC Estimation and Database Creation}

\subsection{Algorithm \& Flowchart for SOC Estimation as Shown in Figure 7}

Step 1: Initialize the Arduino and set the voltage to zero

Step 2: Set the baud rate to establish communication between the Arduino and PC

Step 3: After determining the Amp hour of the Li-ion battery that will feed into the analog pin of the Arduino its equivalent digital value (ADC Value) is stored in it.

Step 4: Based on the updated battery status, the remaining usage hours of the battery will be computed Step 5: Cost of charging will vary depending on the charging distance and time Step 6: Repeat from Step3

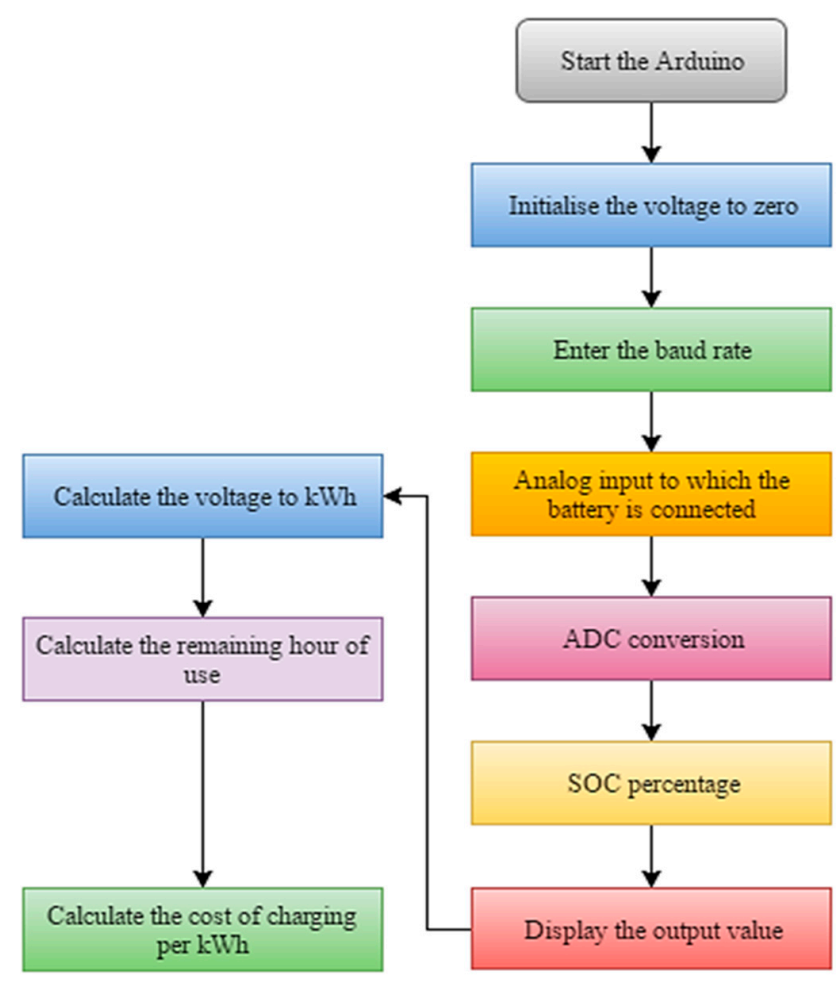

Figure 7. SOC estimation flowchart. 


\subsection{Database Creation}

The database creation is done with the help of the MySQL workbench, which is the unified tool for database creation. Workbench provides data modeling and a comprehensive administration tool for server configuration. The database architect visually designs an interface to generate and manage the pre-loaded data from its virtual memory. The data modeler is involved in creating complex models to deliver the feature changes in the data. In the server configuration, the initialization of serial data from the Arduino is patched through the serial transmission. The main database receives the information and it assigns the database id (127.0.0.1). The server initially displays the data fetched with the help of PHP language. The PHP server-side script language is used for webpage development based on flowchart represented in Figure 8. The data read from the port like SOC and Amp/hour is displayed on the webpage. If the data fails to arrive from the serial port to the server it rolls back to its initial stage. Then the server enables the source and destination option for the user to access the data. Based on the user input the server tries to handle the preloaded data from its database management system. The charging station distance, price and slot availability may vary based on the updating of the server from the vendor side. Based on the availability, the user may prefer a charging station. By choosing the option book, the user can book a slot. Once the booking of a slot is done the server will update its database and send the information to the user and vendor.

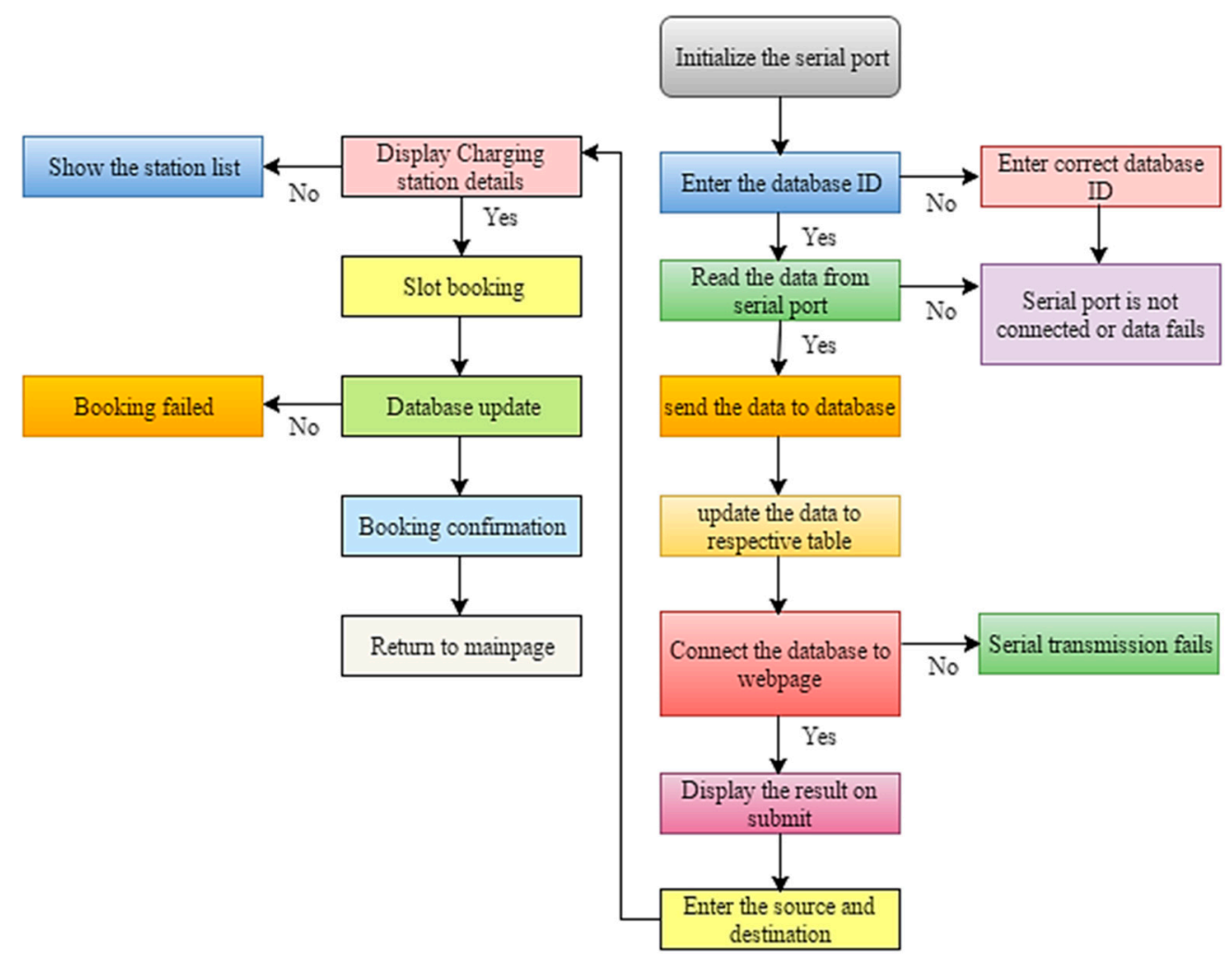

Figure 8. Flowchart for database creation.

\section{Area of Charging Station Selection}

In this work the area chosen to identify the CS locations is between SRM and Chengelpettu (NH47), a part of Chennai in South India. As shown in the Google Map (Figure 9) the distance between each CS location is roughly indicated. 


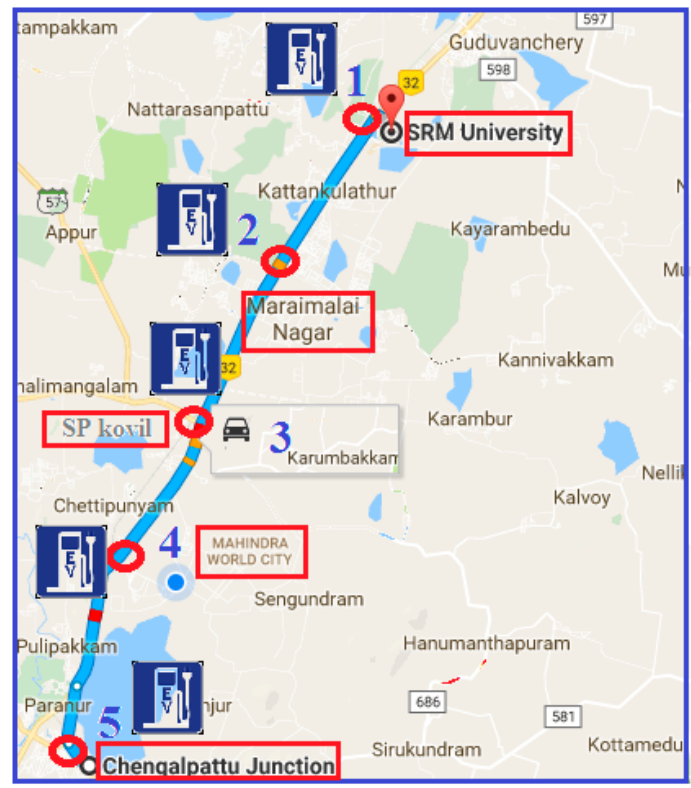

Figure 9. Google map-tested charging station selection.

In India, as the EV market is comparatively small, so users often cannot find any EV charging infrastructure along a journey path. In view of this aspect the system assumes CS is available at fuel stations. The price of electricity $(\mathrm{kWh})$ for charging the EVs varies predominantly by considering the characteristics like the distance between the CS, volume of EVs, the number of charging slots available and ownership of the charging infrastructure, as shown in Table 3. The table illustrates that with reference to charging station 1 (SRM University), the approximate volume of EVs in this location is 3600 per day. A fast charging facility is available at this location, while it is left up to the user preference to book a slot in the same location, then the cost of charging will get increase significantly. Considering the charging station 3 (SP Kovil), due to the unavailability of fast charging points, EV traffic density is comparatively low in this region, so the time taken to charge the vehicle is very high whereas the cost of charging will be decreased.

Table 3. Characteristics of charging stations with reference from Google Map.

\begin{tabular}{|c|c|c|c|c|c|}
\hline $\begin{array}{l}\text { Charging Station } \\
\text { Locations }\end{array}$ & $\begin{array}{l}\text { Distance } \\
\text { Reference from SRM } \\
\text { University (1) in km }\end{array}$ & $\begin{array}{l}\text { Population of the EV } \\
\text { Estimated Per Day }\end{array}$ & $\begin{array}{c}\text { No. of Charging } \\
\text { Point } \\
\text { Availability }\end{array}$ & $\begin{array}{c}\text { Fast } \\
\text { Charging } \\
\text { SlotsAvailability }\end{array}$ & $\begin{array}{l}\text { Reserved/Not } \\
\text { Working }\end{array}$ \\
\hline 1 & 0 & 3600/Day & 35 & Yes & 2 \\
\hline 3 & 1.02 & 1100/Day & 23 & No & 4 \\
\hline 4 & 2.02 & 5600/Day & 41 & Yes & 4 \\
\hline 5 & 5.17 & 3200/Day & 38 & Yes & 4 \\
\hline
\end{tabular}

\section{Results and Discussion}

The SOC of a battery is periodically measured by the Arduino and the same is transferred and/to store the data in the database. This data is connected seamlessly to a server, such that the user, vendor and concerned parties may use this SOC data to improve the energy management system and to utilize the energy more efficiently as well. Once the SOC is received from the Arduino on the PC, the PC will store the data into the server. The below webpage shows live data that has been received from the Arduino. Upon selecting the specific parameter (SOC, $\mathrm{mAh}$ ) the data stored in the database will be linked to the webpage and displayed. The user can find the existing charging stations in between the source and destination journey. Figure 10 shows the homepage of the communication network which 
is displayed when the user opens the webpage. The webpage is created with the options for the SOC, amp-hours and total cost.

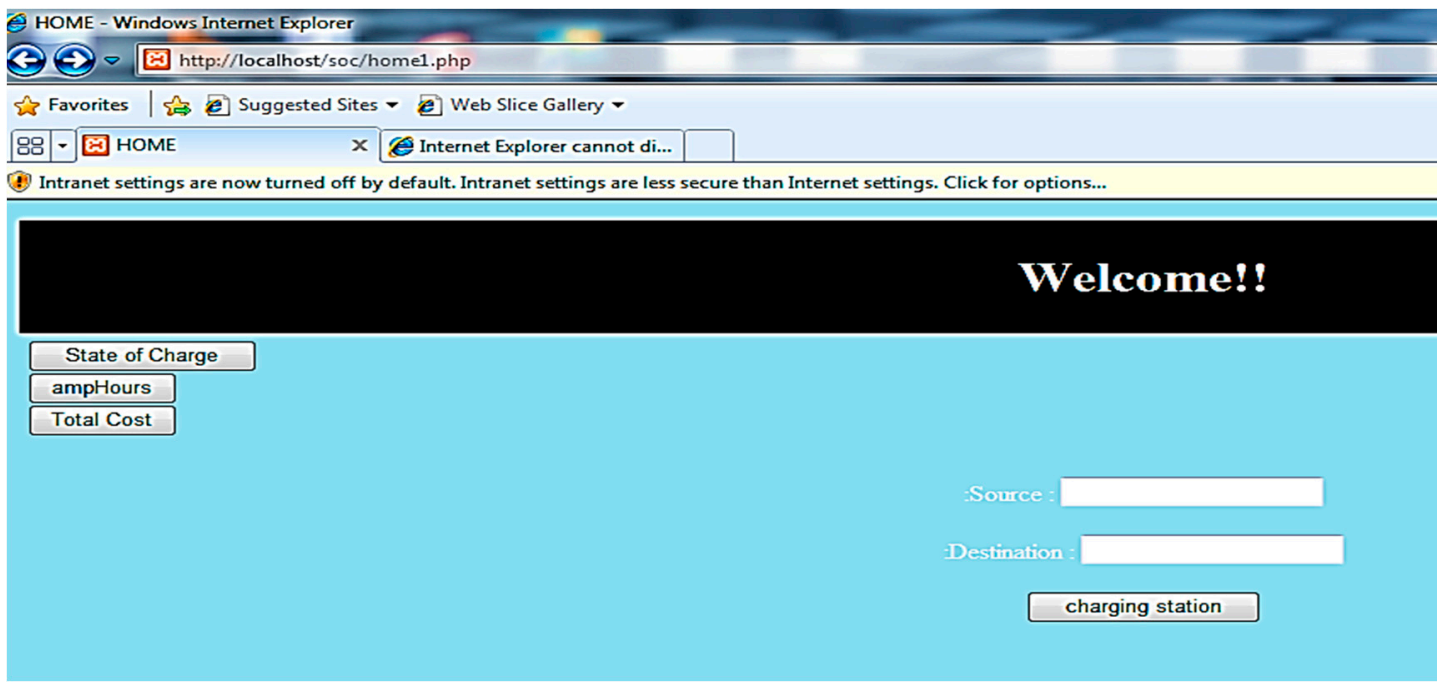

Figure 10. Homepage for charging slot reservation.

Upon giving the inputs in these options the result will be displayed as shown in Figure 11. This architecture ensures the charge planning strategy of EV are optimized in consequence the user can know the details of charging stations, charging slot, the cost of charging and distance need to travel to reach the near/far charging station.

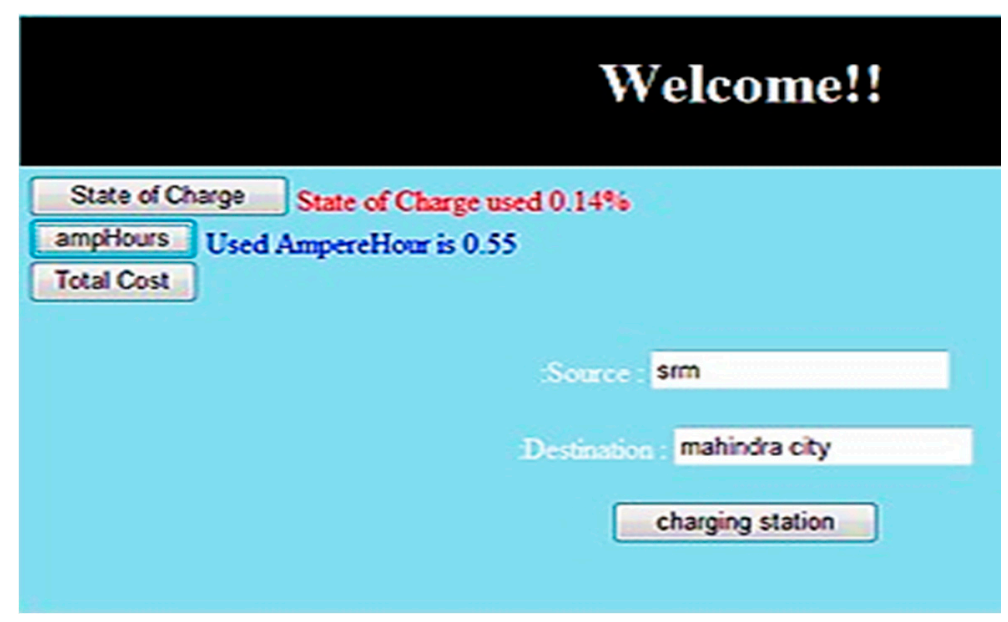

Figure 11. Estimated SOC Value.

As shown in Figure 11, the charging parameters (SOC, kWh, cost, distances) were taken into account, so as to fulfill the future electric transportation requirements. That is, when the user does not have any idea about city and destination distances, after that the user may face trouble with charging the vehicle on the way if required. Consider while the user has to travel from the source location (SRM) to the destination location (Mahindra City), next the user can $\log$ into the webpage and search for available charging stations in between the location SRM and Chengalpattu as shown in Figure 12. The webpage is linked to Google Maps, it searches for existing charging stations and displays them for the user's convenience. The webpage created not only shows the charging stations, but it helps the user know about other information like 
cost per $\mathrm{kWh}$, the total number of charging slots available, the number of free slots available, the number of slots already booked by other EV users and the distance between the user's location to the destination location. Shortly the user can enter the slot number and station name, and a booking will get confirmed.

\section{Charging Stations From : SRM To : CHENGELPET}

\begin{tabular}{|c|c|c|c|c|c|}
\hline Charging Station & Cost per KWH & Stots & Avalability & Booked & Distance \\
\hline SRM & 16.35 & 6 & s & 1 & 0 \\
\hline MARAIMALAI NAGAR & 9.64 & 4 & 2 & 2 & 0.75 \\
\hline MAHINDRA CITY & 18.65 & 9 & 3 & 6 & 2.02 \\
\hline CHENGELPETTU & 12.23 & 5 & 0 & s & 5.17 \\
\hline \multicolumn{6}{|c|}{ Enter slot: : } \\
\hline \multicolumn{6}{|c|}{ Enter station name } \\
\hline & & book & & & \\
\hline
\end{tabular}

Figure 12. Charging station reservation.

The serial port which reads the output of the Arduino as shown in Figure 13, where the voltage is read and displayed by the Arduino in the serial port monitor through converting the analog value to a digital value. There are three different cases taken into concern, in which a fully discharged battery of about $0.06 \mathrm{~V}$ has got $1.27 \%$ of charge, whereas the partially discharged battery of about $3.65 \mathrm{~V}$ contains $73 \%$ of charge remaining and a fully charged battery of about $5 \mathrm{~V}$ has $100 \%$ charge. The displayed results are in the range of 0 to $5 \mathrm{~V}$ because the Arduino can read when the input is either $3.3 \mathrm{~V}$ or $5 \mathrm{~V}$. Thus the battery voltage is converted to demonstrate in the range of 0 to $5 \mathrm{~V}$.

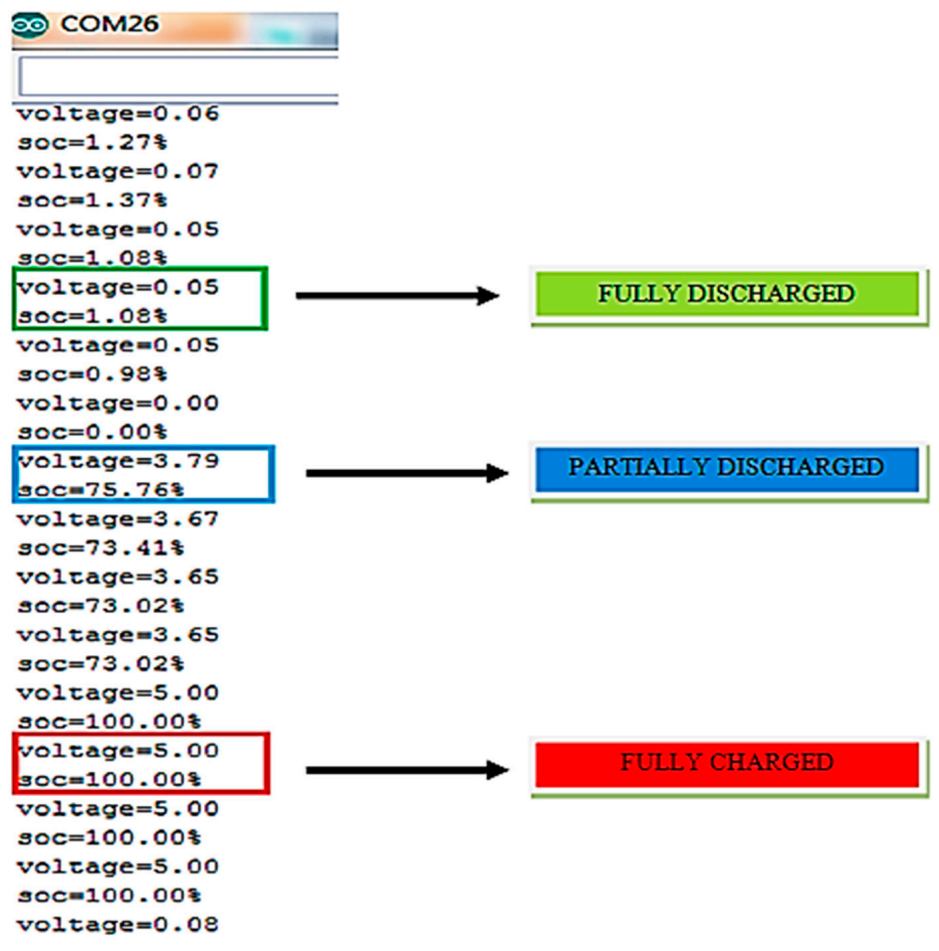

Figure 13. SOC estimated through the Arduino device. 
The database contains the charging station details in the form shown in Figure 14, which is displayed to the user when the source and destination are entered in the webpage.

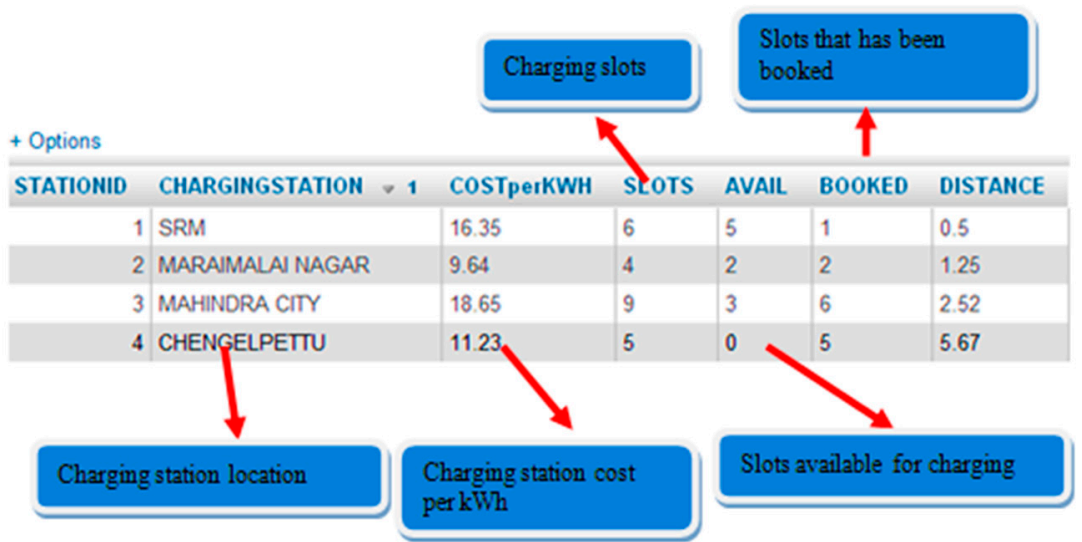

Figure 14. Database of charging stations.

The output of the Arduino is linked to the database shown in Figure 15, which contains the table of all the data that are obtained by the Arduino and linked to the user webpage. The earliest or the latest data is displayed when the user clicks on the button on the webpage.

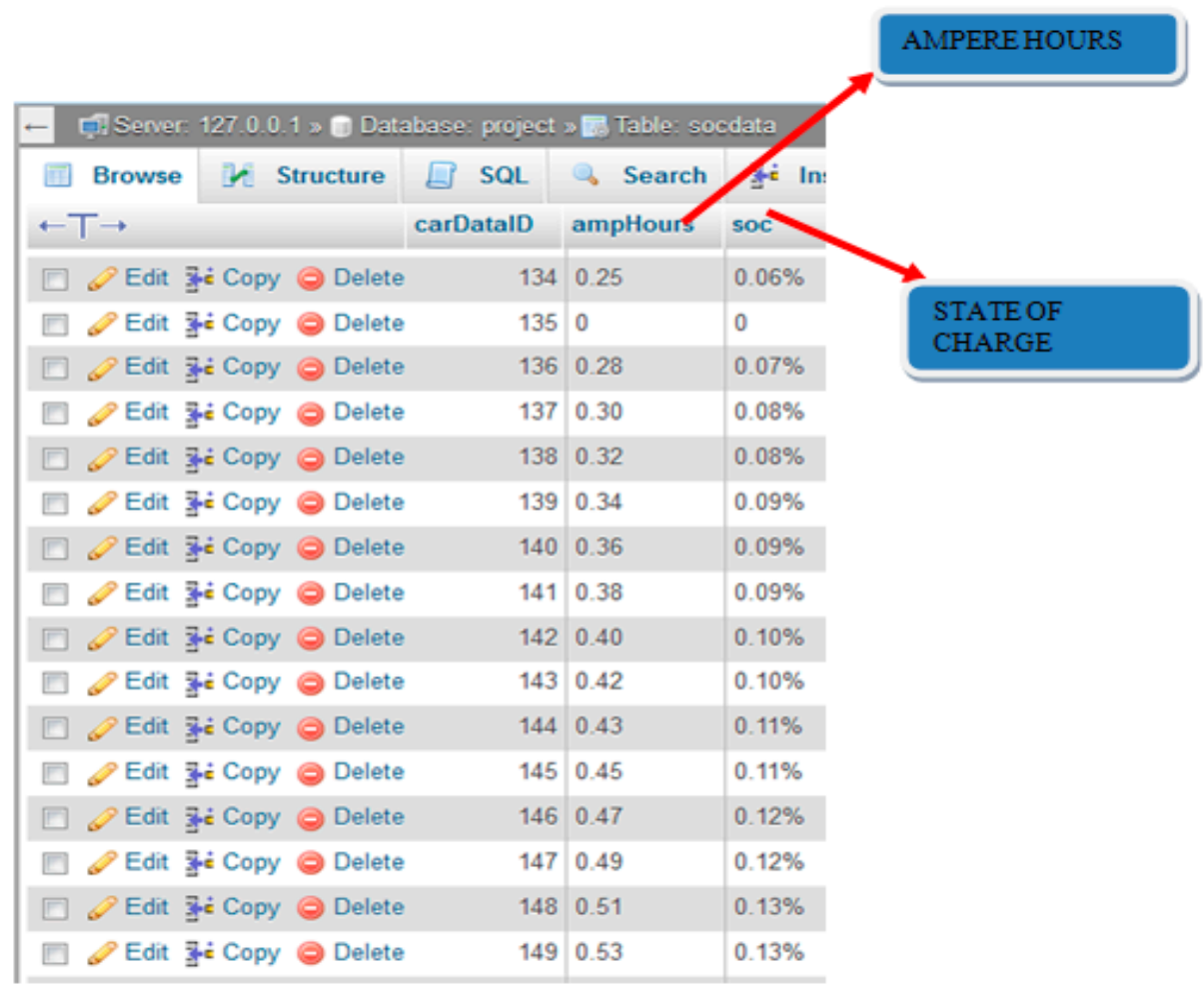

Figure 15. Database of SOC data.

In the case of multiple vehicle scenarios based on the SOC availability, the user can book a slot at the available charging stations, as shown in Figure 16.

This system has been considered for five EVs with different SOC levels. The vehicle 1 and vehicle 2 users have the same location of Maraimalai Nagar (MM Nagar) for charging, therefore, the cost per $\mathrm{kWh}$ and distance remains the same. The vehicle 3 user has reserved the SRM location for charging, 
whereas, the vehicle 4 and vehicle 5 users reserved other charging stations as their SOC is sufficient to reach the destination. Note that the cost per $\mathrm{kWh}$ varies with respect to available charging stations. Thus, it is left up to the user preference to choose the desired charging slot in the appropriate station.

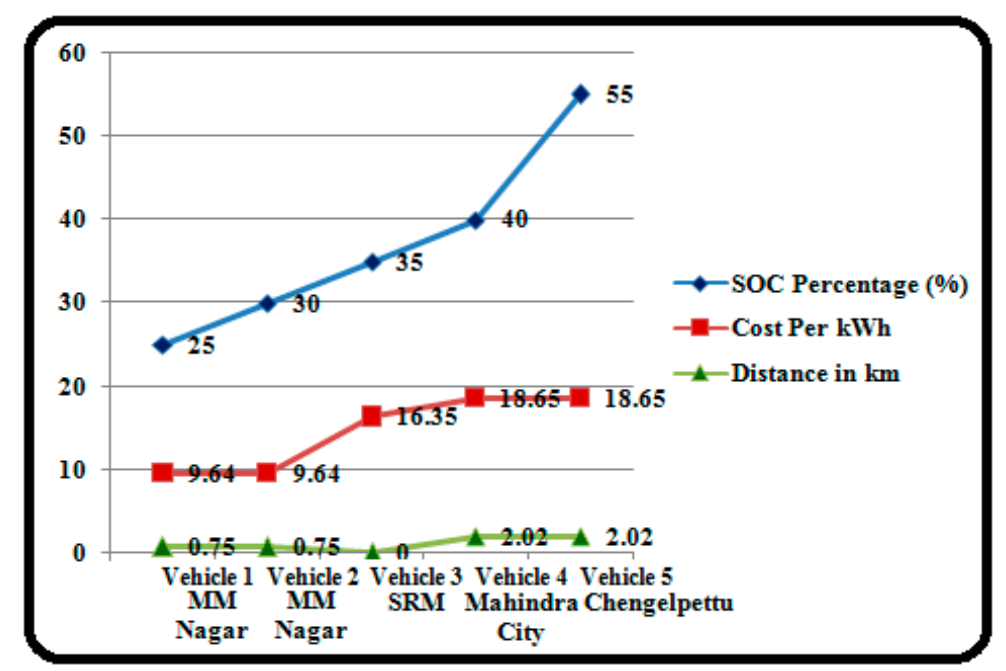

Figure 16. EVs Charging Slot Reservation Chart.

\section{Conclusions}

The proposed approach will overcome the charge scheduling limitations posed by EVs. By communicating vital parameters like SOC to the user through a proper interface, EVs can be used more efficiently and effectively. The user can save a lot of time in waiting for charging slots at the charging station by using this framework. Further, the applications developed are based on the Java and Android platforms which can be improved further according to future technological advancements thereby giving more flexibility to the network system. As a part of our future work, load forecasting may be incorporated into the webpage so as to ensure the reliability of the grid in the charging infrastructure side, and the user will charge the electric vehicle accordingly, which leads to the evolution of vehicle to grid communication and vice versa.

Author Contributions: Bharatiraja Chokkalingam and Sanjeevikumar Padmanaban as developed the proposed research concept and developed the complete study with implemented results and wrote the article; Pierluigi Siano as contributed his experience in Smart Grid system for further development and verification of theoretical concepts and involved in providing suggestion to wrote the article; Ramesh Krishnamoorthy and Raghu Selvaraj involved in the work to set the task in numerical study and assisted with authors to implement and moreover to verify the proposal as researchers and involved in developing the concept and wrote the article as co-authors.

Conflicts of Interest: The authors declare no conflict of interest.

\section{References}

1. Hayes, J.G. Battery Charging Systems for Electric Vehicles. In Proceedings of the IEE Colloquium on Electric Vehicles-A Technology Roadmap for the Future (Digest No. 1998/262), London, UK, 5 May 1998.

2. Su, W.; Eichi, H.; Zeng, W.; Chow, M.-Y. A survey on the electrification of transportation in a smart grid environment. IEEE Trans. Ind. Inf. 2012, 8, 1-10. [CrossRef]

3. Moura, T.; Moura, F. Vehicle-to-grid systems for sustainable development: An integrated energy analysis. Technol. Forecast. Soc. Chang. 2008, 75, 1091-1108.

4. Ciaravolo, R.J.; Cousland, A.W.; Blieden, G.; Hosseinzadeh, N. The design of a battery charger and charging management system for an electric vehicle. In Proceedings of the 45th International Universities Power Engineering Conference (UPEC2010), Cardiff, UK, 31 August-3 September 2010; pp. 1-6. 
5. Haghbin, S.; Kha, K.; Lundmark, S.; Alaküla, M. Integrated chargers for EV's and PHEV's: Examples and new solutions. In Proceedings of the IEEE International Conference on Electrical Machines (ICEM), Rome, Italy, 6-8 September 2010; pp. 1-6.

6. Shao, S.; Pipattanasomporn, M.; Rahman, S. Grid integration of electric vehicles and demand response with customer choice. IEEE Trans. Smart Grid 2012, 3, 543-550. [CrossRef]

7. Verzijlbergh, R.A.; De Vries, L.J.; Lukszo, Z. Renewable Energy Sources and Responsive Demand. Do We Need Congestion Management in the Distribution Grid? IEEE Trans. Power Syst. 2014, 29, $2119-2128$. [CrossRef]

8. Chang, W.-Y. The State of Charge Estimating Methods for Battery: A Review. ISRN Appl. Math. 2013, 2013, 953792. [CrossRef]

9. Zhang, Y.; Gjessing, S.; Liu, H.; Ning, H. Securing vehicle-to-grid communications in the smart grid. IEEEWirel. Commun. 2013, 20, 66-73. [CrossRef]

10. Xie, F. Research on electric vehicle charging station load forecasting. In Proceedings of the International Conference on Advanced Power System Automation and Protection (APAP'11), Beijing, China, 16-20 October 2011; Volume 3, pp. 2055-2060.

11. Etezadi-Amoli, M.; Choma, K.; Stefani, J. Rapid-Charge Electric-Vehicle Stations. IEEE Trans. Power Deliv. 2010, 25, 1883-1887. [CrossRef]

12. Foley, A.M.; Winning, I.J.; Ó Gallachóir, B.P. State-of-the-Art in Electric Vehicle Charging Infrastructure. In Proceedings of the 2010 IEEE Vehicle Power and Propulsion Conference (VPPC), Lille, France, 1-3 September 2010; pp. 1-6.

13. Faria, R.; Moura, P.; Delgado, J.; de Almeida, A.T. Managing the Charging of Electrical Vehicles: Impacts on the Electrical Grid and on the Environment. IEEE Intell. Transp. Syst. Mag. 2014, 6, 54-65. [CrossRef]

14. Ramesh, K.; Bharatiraja, C.; Raghu, S.; Vijayalakshmi, G.; Sambanthan, P.L. Design and Implementation of Real-Time Charging Optimization for Hybrid Electric Vehicles. Int. J. Power Electron. Drive Syst. 2016, 7, 201-291. [CrossRef]

15. Chen, Z.; Li, X.; Shen, J.; Yan, W.; Xiao, R. A Novel State of Charge Estimation Algorithm for Lithium-Ion Battery Packs of Electric Vehicles. Energies 2016, 9, 710. [CrossRef]

16. Wang, Y.; Zhang, C.; Chen, Z. On-line battery state-of-charge estimation based on an integrated estimator. Appl. Energy 2017, 185, 2026-2032. [CrossRef]

17. Chynoweth, J.; Chung, C.-Y.; Qiu, C.; Chu, P. Smart electric vehicle charging infrastructure overview. In Proceedings of the IEEE Power and Energy Society Conference on Innovative Smart Grid Technologies Conference (IEEE-ISGT'14), Washington, DC, USA, 19-22 February 2014; pp. 1-5.

18. Su, W.; Chow, M.-Y. Computational intelligence-based energy management for a large-scale PHEV / PEV enabled municipal parking deck. Appl. Energy 2012, 96, 171-182. [CrossRef]

19. Mukherjee, C.; Gupta, A. A review of charge scheduling of electric vehicles in the smart grid. IEEE Syst. J. 2015, 9, 1541-1553. [CrossRef]

20. Jin, C.; Tang, J.; Ghosh, P. Optimizing electric vehicle charging: A customer's perspective. IEEE Trans. Veh. Technol. 2013, 62, 2919-2927. [CrossRef]

21. Ma, T.; Mohammed, O. Optimal charging of plug-in electric vehicles for a car-park infrastructure. IEEE Trans. Ind. Appl. 2014, 50, 2323-2330. [CrossRef]

22. Cheng, K.W.E.; Divakar, B.P.; Wu, H.; Ding, K. Battery-Management System (BMS) and SOC Development for Electrical Vehicles. IEEE Trans. Veh. Technol. 2010, 60, 76-88. [CrossRef]

23. Chen, Z.; Xia, B.; Mi, C.C. A novel state-of-charge estimation method for a lithium-ion battery pack of electric vehicles. In Proceedings of the 2015 IEEE Transportation Electrification Conference and Expo (ITEC), Metro Detroit, MI, USA, 14-17 June 2015.

24. Zhang, C.; Jiang, J.; Zhang, L.; Liu, S.; Wang, L.; Loh, P.C. A Generalized SOC-OCV Model for Lithium-Ion Batteries and the SOC Estimation for LNMCO Type equation Battery. Energies 2016, 9, 900. [CrossRef]

(C) 2017 by the authors. Licensee MDPI, Basel, Switzerland. This article is an open access article distributed under the terms and conditions of the Creative Commons Attribution (CC BY) license (http:/ / creativecommons.org/licenses/by/4.0/). 